\title{
Experimental Study of the Performance Test for the Infusion Monitoring System
}

\author{
XU Zhihui, LI Weizhong, XIAO Yongjun* \\ HuBei Engineering University \\ School of Physics and Electronic Information Engineering \\ Xiaogan, China \\ E-mail: 75694676@qq.com
}

\begin{abstract}
Comparison with conventional manual adjustment to control the drop speed in clinical infusion, the infusion monitoring system can achieve much more high reliability and efficiency, and is easy to realize the automation of infusion. So the infusion monitoring system has been designed in the last papers. To test the designed system performance, some experiments are done. And the result show that under requirement of the system precision, the time consumption increase with the incensement of speed difference value; Comparing to the conventional PID controller, the fuzzy-PID controller can achieve high precision and little stabilizing time consumption.
\end{abstract}

Keywords-infusion monitoring system; system precision; stabilizing time; experimental study

\section{INTRODUCTION}

Intravenous infusion dispensation is widely used in clinical treatment ${ }^{[1][2]}$, However, Manual adjustment to control drop speed with the character of inadequate accuracy, inconvenience, infusion abnormal and end is difficult to find, is usually adopted in most hospital over many decades and maybe cause medical malpractice ${ }^{[1][3][4][5]}$

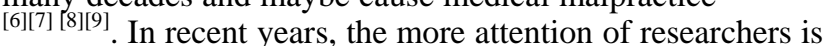
pay on the automatic infusion system ${ }^{[6][8][10]}$.

In the last papers, the infusion monitoring system is designed based on the STM32F103 microcontroller, but a little experiments has been done, so in this paper, the experiment for system performance test is done, it includes system precision test, time consumption test, and comparison under different control arithmetic. At last, the experimental data is analyzed and some conclusions are achieved in this paper.

\section{THE DESCRIPTION OF DESIGNED INFUSION MONITORING SYSTEM}

The infusion monitoring system is illustrated in figure 1 . The whole system is consisted of the control module, step motor and its driver, sheave, infusion bottles and infusion monitoring sensor. The infusion bottles can be pull up or down by step motor to adjust the infusion speed, while the infusion monitoring sensor can real-time measure the drop speed and the speed signal is sent to microcontroller after the process of signal shaper.

In the control module, the control core is the STM32F103 microcontroller, and the expand keyboard of the STM32F103 is used for the input of preset speed or other command, LCD module is used for the real-time display of drop speed and infusion residual quantity. The ADC module, as the Peripheral of STM32F103, is in charge of conversion from analog to digital. The PWM signal, produced by the PWM module, is sent to step motor driver and drive the motor to rotate. The infusion speed sensor, adopted in this system, is one pairs of the infrared emitting and receiving diode.

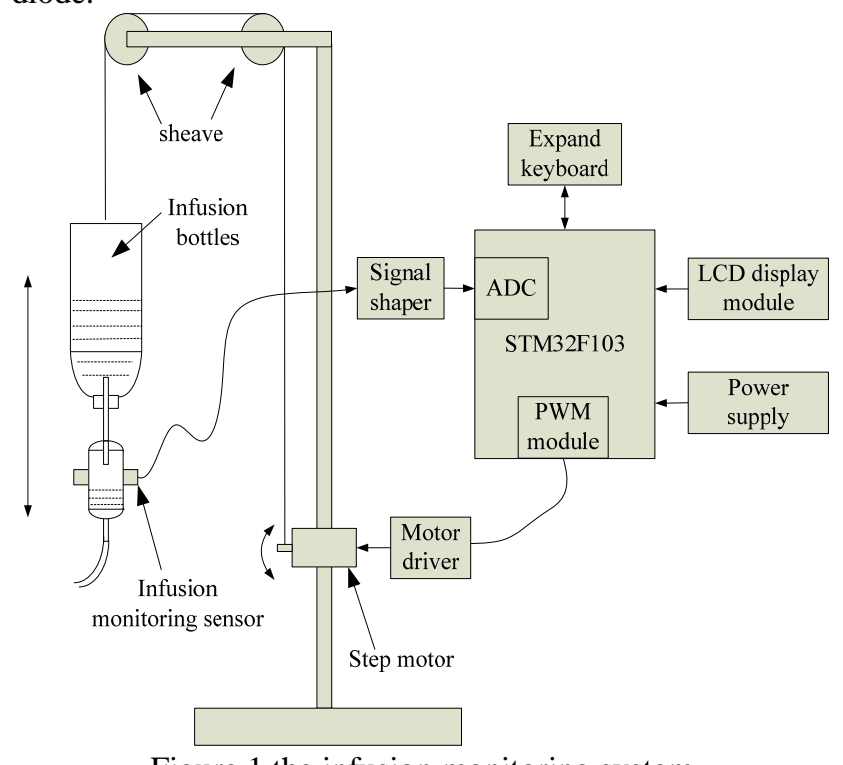

Figure 1 the infusion monitoring system

\section{PERFORMANCE TEST PLAN FOR THE DESIGNED SYSTEM}

For the designed system, the important parameters are the system precision and stabilizing time. However, in the actual infusion control system, if it needs to improve the precision, the stabilizing time would be increasing, so there is always a contradiction between the precision and stabilizing time. So the eclectic performance is finished through the application of some intelligent control methods.

So in this paper, the experiment is done to test the system precision, the stabilizing time and the performance in different control arithmetic. The test instrument and conditions is illustrated in table 1.

Table 1 test instrument and conditions

\begin{tabular}{|c|l|}
\hline item & \multicolumn{1}{c|}{ Parameters } \\
\hline Time scale & $\begin{array}{l}\text { The Precision Professional Stopwatch } \\
\text { (PC6230), with the character of tow } \\
\text { rows display, 1/100 second, and measure }\end{array}$ \\
\hline
\end{tabular}




\begin{tabular}{|c|c|}
\hline & $\begin{array}{l}\text { up to } 9 \text { hours } 59 \text { minutes and } 59.99 \\
\text { seconds, } 30 \text { recallable lap and split } \\
\text { memories. }\end{array}$ \\
\hline Height scale & Meter stick \\
\hline Test conditions & Indoor with straight background-light \\
\hline Speed checking & $\begin{array}{l}\text { Manual scale after infusion speed } \\
\text { stabilized }\end{array}$ \\
\hline $\begin{array}{c}\text { System } \\
\text { parameters }\end{array}$ & $\begin{array}{l}\text { The adjusted range of infusion bottles } \\
\text { height : } 20 \mathrm{~cm}-150 \mathrm{~cm} \text {, the infusion } \\
\text { speed: } 20-140 \text { (drops per second, and } \\
\text { called dps in follows) }\end{array}$ \\
\hline
\end{tabular}

\section{EXPERIMENT AND DATA ANALYSIS}

\section{A. $\quad$ system precision test without regard to the adjusted time}

Without considering the stabilizing time, the system precision test with the same speed difference value between the current speed and preset speed is firstly done for ten times and the data error for every times is shown in figure 2. when the speed difference value is 20dps, the maximum and minimum value of adjusting error are separately $13 \%$ and $3.3 \%$ and the average error is $5 \%$; while the speed difference value is $40 \mathrm{dps}$, the maximum and minimum value are separately $7.5 \%$ and $2.5 \%$ and the average error is $9 \%$. So from the figure, we can infer that the error percentage will increase with the decrease of the speed difference value.

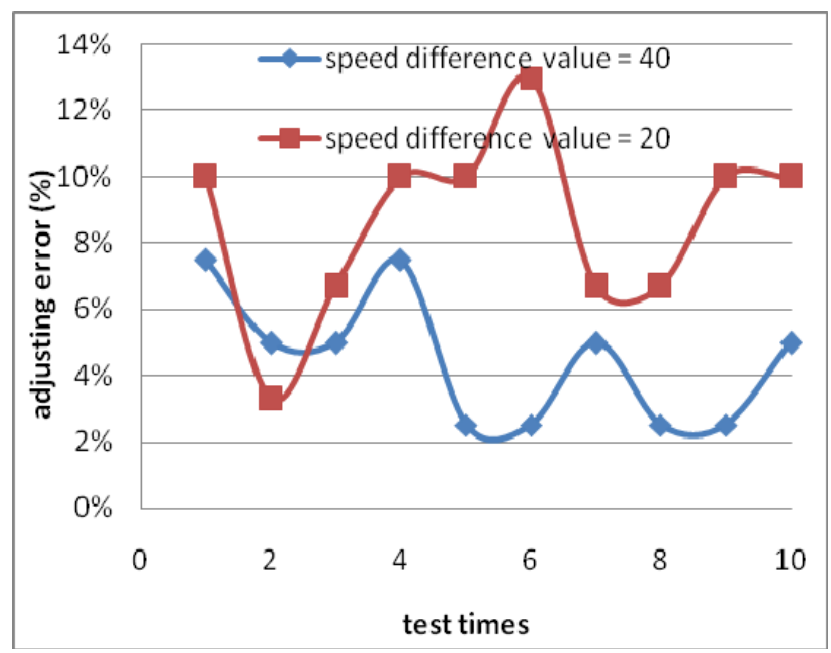

Figure 2 the adjusting error with the same speed differences value and the initial speed $=50 \mathrm{dps}$

Under ignoring the stabilizing time, the stabilizing precision test is done with initial speed $=50$ dps and preset speed $=80 \mathrm{dps}$, the data is shown in figure 3 , so we can see that it is 160 s that system precision enter into stabilizing state.

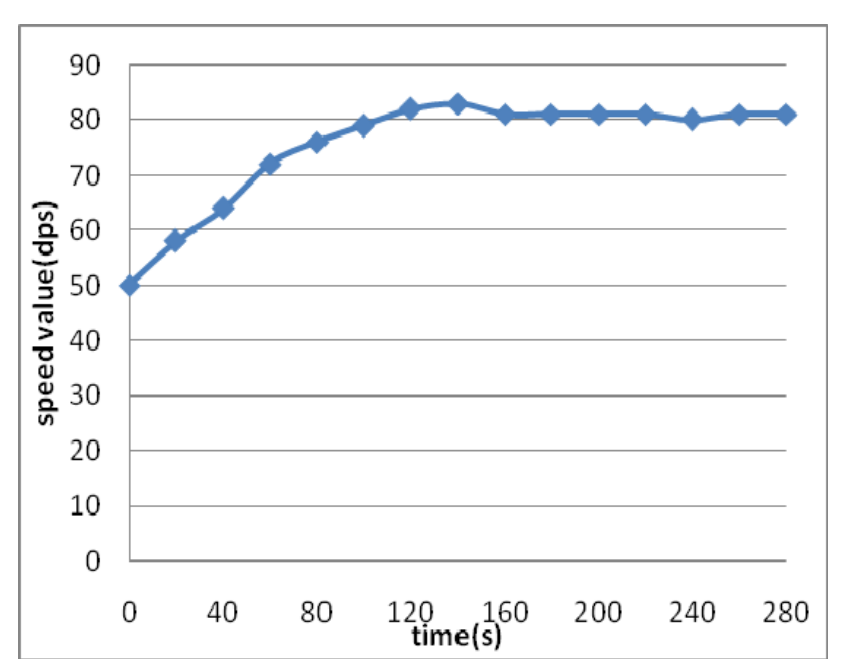

Figure 3 precision test with initial speed $=50 \mathrm{dps}$ and preset speed $=80 \mathrm{dps}$

At last, the dynamic test for the designed system with the initial speed $=20$ and difference value $=30$ is done, and the data is illustrated in table 2. In this experiment, if the current speed value is $48 \mathrm{dps}$, the next test initial speed is $48 \mathrm{dps}$ and the preset speed value is $78 \mathrm{dps}$, and so on. From this table, the adjusting error is restively small and can meet the system requirement.

Table 2 experimental result for infusion speed with the initial speed $=20 \mathrm{dps}$

\begin{tabular}{|c|c|c|c|}
\hline $\begin{array}{c}\text { preset speed } \\
\text { (dps) }\end{array}$ & $\begin{array}{c}\text { Adjusted } \\
\text { speed(dps) }\end{array}$ & $\begin{array}{c}\text { Speed } \\
\text { error(dps) }\end{array}$ & $\begin{array}{c}\text { Error } \\
\text { percentage }\end{array}$ \\
\hline 50 & 48 & 2 & $6.7 \%$ \\
\hline 78 & 79 & 1 & $3.3 \%$ \\
\hline 109 & 108 & 1 & $3.3 \%$ \\
\hline 138 & 136 & 2 & $6.7 \%$ \\
\hline 106 & 105 & 1 & $3.3 \%$ \\
\hline 75 & 73 & 2 & $6.7 \%$ \\
\hline 43 & 44 & 1 & $3.3 \%$ \\
\hline
\end{tabular}

\section{B. The stabilizing time test under the requirement precision}

Under the meeting for the requirement of system precision, the stabilizing time is done and the speed difference value are separately $10 \mathrm{dps}$, 20dps, 20dps, 30dps, 40dps, 50dps, 60dps, 70dps, 80dps and 90dps, the initial speed is 50dps, the experiment repeat ten times for every speed difference value and finally the average value is used for curve plotting. The experimental result is shown in figure 4.

From the figure, the time consumption increase with the incensement of speed difference value except that the speed difference value is $10 \mathrm{dps}$, and this is up to ours prediction. 


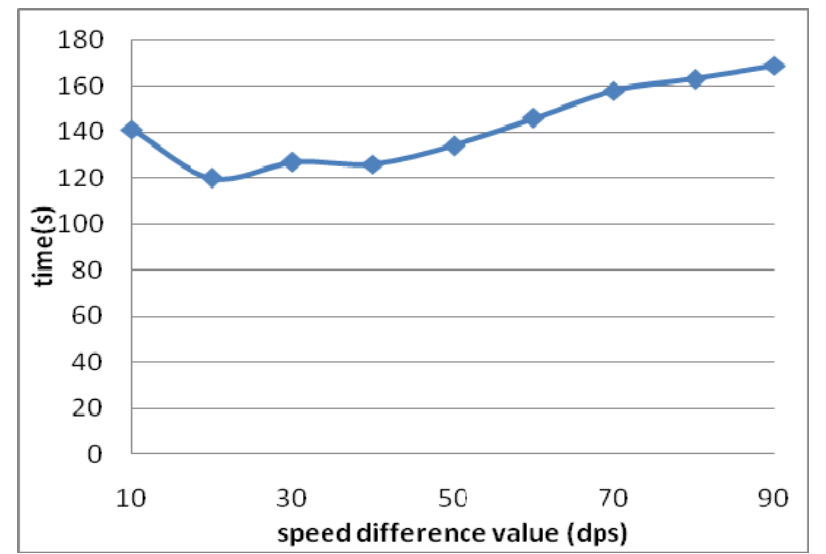

Figure 4 The stabilizing time with different speed difference value and the initial speed $=50$

\section{C. system performance test under different control arithmetic}

A proportional-integral-derivative controller (PID controller) is a generic control loop feedback mechanism (controller) widely used in industrial control systems - a PID is the most commonly used feedback controller. However, the parameters of Proportional gain, integral gain and derivative gain cannot be modified on line in actual system. The fuzzy control can achieving high robust and isn't lie on the precise mathematic module ${ }^{[11[12][13]}$. So the fuzzy-PID controller combined the PID controller with the fuzzy controller, is designed and applied into this system.

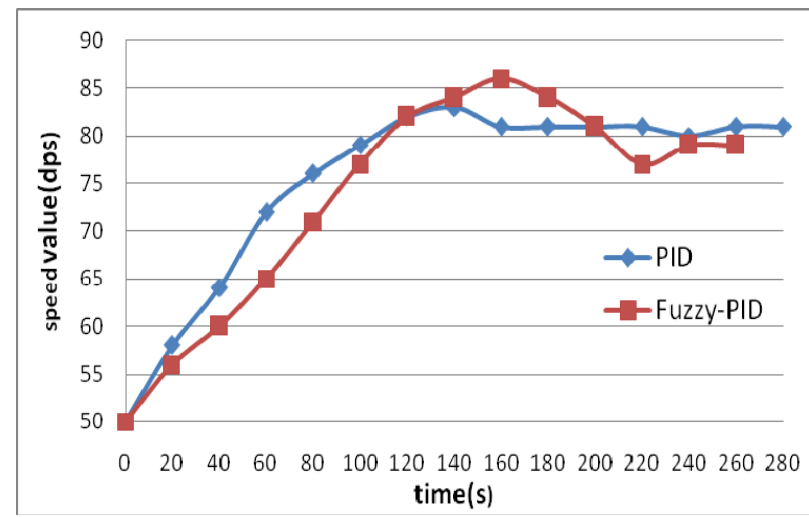

Figure 5 the performance comparison between PID and the fuzzy-PID controller

To comparing the performance between the PID controller and the Fuzzy-PID controller, the experiment is done, and the result is shown in figure 5. For the fuzzy-PID controller, the stabilizing time is 160s; while the stabilizing time is 240s for the PID controller.

\section{CONCLUSIONS}

Based on the designed infusion control system, some experiments are done and the data is canalized, the conclusion is illustrated as follows:
- If the stabilizing time is ignored, the system can achieve high precision and the error and error percentage can separately reach to $1 \mathrm{dps}$ and $2.5 \%$.

- Under requirement of the system precision, the time consumption increase with the incensement of speed difference value.

- Comparing to the conventional PID controller, the fuzzy-PID controller can achieve high precision and little stabilizing time consumption.

Generally, the designed system can be widely used in monitoring and management in the course of the infusion to advance the working conditions of medical staffs and reduce the medical errors in the small hospitals.

\section{ACKNOWLEDGMENT}

We would like to express our thanks to the professors Xinming Wang and ours students for their valuable discussions and helps to improve this paper and ready for our experiment.

\section{REFERENCES}

[1] Safety issues with patient-controlled analgesia. Part II: How to prevent errors[D]. ISMP Medication Safety Alert; 2003 July 24.

[2] Derrick JL, Ho AM, Cho AM. Consequences of syringe size sensor malfunction in a modern infusion pump[J], Anaesthesia and intensive care, 2003, V. 31 no. $1: 75-79$

[3] Smetzer JL, Vaida AJ, Cohen MR, et al. Findings from the ISMP Medication Safety Self-Assessment ${ }^{\circledR}$ for Hospitals. Jt Comm J Qual Safety 2003; 29: 586-597.

[4] Frequent problems with medication systems noted during ISMP hospital evaluations. Part 2. ISMP Medication Safety Alert 1998 June 17. Available at:

[5] Maddox RR, Williams CK, Oglesby H, et al. Clinical experience with patient-controlled analgesia using continuous respiratory monitoring and a smart infusion system[J]. Am J Health Syst Pharm 2006; 63: 157-164.

[6] Neff TA, Fischer JE, Schulz G, Baenziger O, Weiss M. Infusion pump performance with vertical displacement : effect of syringe pump and assembly type[J]. Intensive care medicine, V27, no. 1, $2001: 287-291$

[7] Overdyk F, Carter R, Maddox R, et al. Continuous oximetry/capnometry monitoring reveals frequent desaturation and bradypnea during patient controlled analgesia. Anesth Analg 2007; 105: 412-418.

[8] SHAN Wei. Design and implementation of the infusion monitoring system based on AT89S52 [D]. HeFei: HeFei University of technology, 2009 (in chinese)

[9] HUO Lifeng. Research and implement of the distributed infusion control/monitoring system [D]. TaiYuan: TaiYuan University of technology, 2007 (in chinese)

[10] W. Hoffmann. Computer controlled tit rat ion with piston burette or peristaltic pump a comparison [J]. Fresenius J Anal Chem. 1996, (356):303-305

[11] S Tzafestas, N Papanikolopoulos. Incremental fuzzy expert PID controls [J]. IEEE, Trans on Industrial Electronics, 1990, 37(5):365371

[12] Y F Li, C C Lau. Development of fuzzy algorithms for servo system [J], IEEE, Control System Magazine, 1989, 9(3): 65-72

[13] Bao-gang Hu, Georgc K I Mann, Raymond G Gosine. New methodology for analytical and optimal design of fuzzy PID controllers [J]. IEEE, Transactions on Fuzzy Systems, 1999, 7(5): 521-539 